\title{
Investigation on fast and energy-efficient heat treatments of AA6082 in HFQ processes for automotive applications
}

\author{
Nan Li ${ }^{1, a}$, Jinghua Zheng ${ }^{1}$, Chao Zhang ${ }^{1}$, Kailun Zheng ${ }^{1}$, Jianguo Lin ${ }^{1}$, and Trevor A. Dean ${ }^{2}$ \\ ${ }^{1}$ Department of Mechanical Engineering, Imperial College London, London SW7 2AZ, UK \\ ${ }^{2}$ School of Mechanical Engineering, The University of Birmingham, Birmingham B15 2TT, UK
}

\begin{abstract}
For HFQ volume production in automotive applications, short heat treatment time is an important factor for efficient and cost effective manufacturing. In this study, fast, efficient and energy saving solution heat treatment (SHT) and ageing processes have been identified based on precipitation nucleation and growth mechanisms and a series of experiments. Material chosen was AA6082, which is an alloy favoured for automotive body structures. The effects of heating rate, soaking temperature and time on SHT processes, and the influence on post mechanical properties, have been characterised. A duplex ageing process integrated paint bake process has been developed, with an optimum ageing condition determined. In addition, the effect of pre-deformation has been analysed.
\end{abstract}

\section{Introduction}

A new forming process, solution Heat treatment, cold die Forming and Quenching (HFQ) process, has been developed for forming lightweight complex-shaped aluminium panel components for automotive and aerospace applications [1]. This process was initially developed based on traditional aluminium heat treatment conditions, which requires long material processing time and high cost in energy and equipment. To enable the HFQ process to be successfully applied in the automotive industry for mass production, heat treatment of Al-alloys with improved energy efficiency in reduced time is a critical requirement. In the process, two main aspects of heat treatment conditions, which are for solution heat treatment (SHT) and ageing, need to be comprehensively studied. AA6082 is a heat treatable aluminium alloy favoured for forming medium-high strength automotive panel components.

In the HFQ process, SHT of the material prior to forming is to dissolve all precipitates into the aluminium matrix and maximise formability of the alloy [1]. Current HFQ practices start with a sheet material in T6/T4 condition, so that the desired state of solid solution can be reached in a short time at a conventional SHT temperature. But it was detected that the standard SHT soaking time may not be sufficient to guarantee the full strength of an HFQed component, which could be caused by a slow heating rate of the material in a furnace. Since the production cost of aluminium sheets in T6/T4 condition is high due to extra processing operations, $\mathrm{O}$ condition is preferred for lower cost. However,

\footnotetext{
${ }^{\text {a }}$ Corresponding author: n.li09@imperial.ac.uk
}

This is an Open Access article distributed under the terms of the Creative Commons Attribution License 4.0, which permits unrestricted use, distribution, and reproduction in any medium, provided the original work is properly cited. 


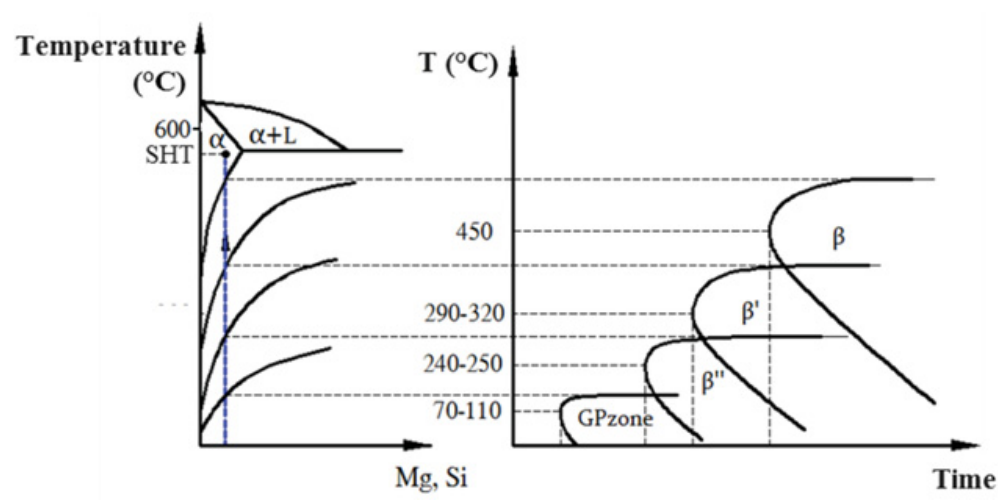

Figure 1. Schematic phase diagram and TTT curves of precipitates in AA6082.

materials in $\mathrm{O}$ condition require longer soaking time (approximately 30 minutes for AA6082-O [2]) at a conventional SHT temperature, which is not unsuitable for high volume production. It has been identified that SHT time can be reduced at a higher soaking temperature [1]. But if the temperature is too high, the mechanical properties of formed parts can be deteriorated [3].

In order to increase the post-form strength of HFQed parts, ageing is required for precipitates hardening of the material. Normally, artificial ageing is performed by exposing the material to an elevated temperature for a long period of time $\left(190^{\circ} \mathrm{C} \times 8\right.$ hours for AA6082 [4]) to allow precipitates to grow. This condition applies well for ageing aluminium sheet products, since the sheet can be coiled and batch-aged with high uniformity. However, when artificial ageing is performed on HFQ formed components, the ageing time makes the process inefficient for high volume production and also needs large expensive ageing facilities. In automotive manufacturing lines, vehicle parts will finally go through a paint bake process $\left(180^{\circ} \mathrm{C} \times 30 \mathrm{~min}\right)$ [5], which can be considered as part of the artificial aging process. Thus, a fast and suitable heat treatment condition prior to paint bake needs to be identified for maximising the post strength of materials.

In this paper, the aforementioned problems are investigated through theoretical studies on precipitation nucleation and growth mechanisms and a series of experiments. The aim is to determine the short-time and low-cost heat treatment conditions for AA6082 for the HFQ process.

\section{Microstructural evolutions in AA6082 during SHT and ageing}

The purpose of heat treatments of 6xxx series aluminium alloys is to obtain desired precipitates at the nanometre level as the mechanical properties of the alloys are controlled by the precipitates. Based on various heat treatments, the precipitate phases that exist in the aluminium alloy can be different. Figure 1 schematically illustrates the phase diagram and time-temperature-transformation (TTT) curves of the primary precipitates in AA6082. The SHT temperature for AA6082 should be limited to approximate $500-585^{\circ} \mathrm{C}$ [4]. In the HFQ process, the precipitates (in any phase) are dissolved during the SHT process and grow to the required size ( $\beta^{\prime \prime}$ phase) during the ageing process. The typical size of precipitates in $\beta^{\prime}$ and $\beta$ phases is much larger than the size in $\beta^{\prime \prime}$ phase [6]. As the bigger precipitates take more time to be dissolved into aluminium matrix [4], the material which contains more $\beta^{\prime}$ and $\beta$ phase precipitates normally needs longer SHT time. A typical ageing process for AA6082 involves heating and soaking the material, so as to provide sufficient energy to allow precipitates to be evenly distributed throughout the material. On a microstructural level, this allows the material to pass through several stages, in particular: $\alpha(\mathrm{SSSS}) \rightarrow$ co-clusters $\rightarrow$ GP zones $(\mathrm{I}) \rightarrow$ GP zones $(\mathrm{II}) / \beta^{\prime \prime}$, which increases the strength of the 
Table 1. Chemical compositions of as-delivered AA6082.

\begin{tabular}{|c|c|c|c|c|c|c|c|c|c|}
\hline Element & $\mathbf{S i}$ & $\mathbf{F e}$ & $\mathbf{C u}$ & $\mathbf{M n}$ & $\mathbf{M g}$ & $\mathbf{C r}$ & $\mathbf{Z n}$ & $\mathbf{T i}$ & Others Total \\
\hline$\%$ & 0.9 & 0.38 & 0.08 & 0.42 & 0.7 & 0.02 & 0.05 & 0.03 & 0.03 \\
\hline
\end{tabular}

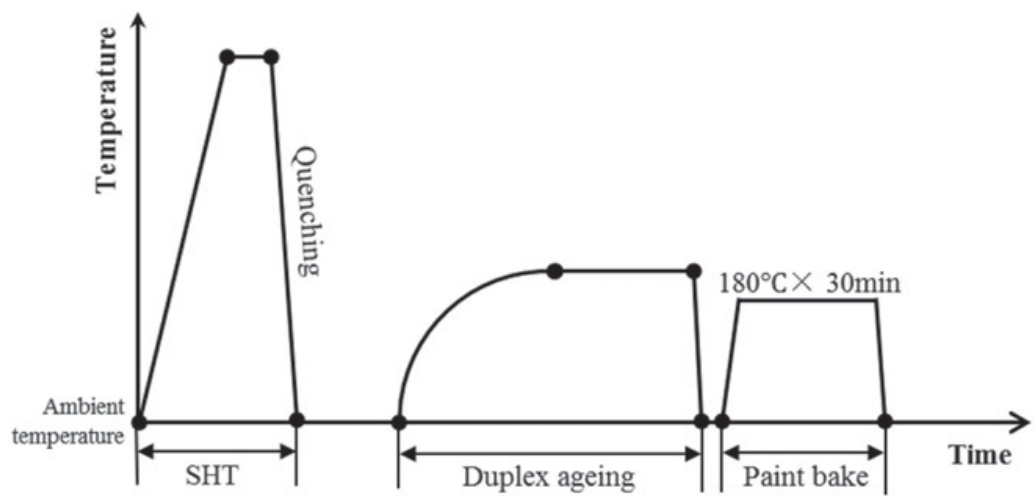

Figure 2. Schematic temperature profiles for SHT and duplex ageing integrated paint bake.

material. However, ageing for a longer time will pass the material through the $\beta^{\prime \prime} \rightarrow \beta^{\prime} \rightarrow \beta$ phases which would induce over-age and reduction in strength [7].

To enhance ageing efficiency, a fast aging method, named two-step aging, has been proposed and accepted as feasible by extensive researchers. This method is to separate the ageing process into two temperature steps. The first step is to control temperature below GP zone solvus in order to generate fine dispersed high fraction of GP zones. The second step is to increase the temperature higher than the GP zone solvus temperature to force GP zone to grow rapidly to $\beta^{\prime \prime}$, which is the main hardening phase of the alloy [7]. The temperatures and time for the two steps are interdependent and a good balance between precipitate density and size has to be obtained. A proper heat treatment can have a positive effect on the paint bake response through the formation of stable GP zones, which can act as nuclei for the formation of the main hardening phase $\beta$ " [8].

\section{Experimental programme}

The as-delivered material is commercial grade AA6082-T6 sheet, with hardness of 120HV. The chemical compositions are listed in Table 1. To facilitate evaluation, the test-piece was designed as a standard uniaxial tensile specimen, following the sub-size dog-bone shape defined by America standard test method (ASTM). The dimensions of gauge section were: $6 \mathrm{~mm} \times 25 \mathrm{~mm}$ (1.5 mm in thickness).

The designed procedure of heat treatments for the HFQ process is schematically illustrated in Fig. 2. For the investigation of SHT, two groups of tests were conducted: (I) AA6082-T6 specimens were heated to conventional SHT temperature $525^{\circ} \mathrm{C}$ under 3 different heating rates $\left(0.2^{\circ} \mathrm{C} / \mathrm{s}, 2{ }^{\circ} \mathrm{C} / \mathrm{s}\right.$, and $20^{\circ} \mathrm{C} / \mathrm{s}$ ) and soaked for 1-15 min; (II) AA6082-O, produced by annealing of the as-delivered sheet, were heated under a fast heating rate to different temperatures $\left(525^{\circ} \mathrm{C}-570^{\circ} \mathrm{C}\right)$ and soak for $1-45 \mathrm{~min}$. All specimens were water quenched and aged under the conventional condition $\left(190^{\circ} \mathrm{C} \times 8\right.$ hours $)$. For the investigation of ageing, by applying the mechanism of two-step ageing, a new process (termed duplex ageing) was proposed, which combines two steps as one with a gradual heating up procedure. All specimens were fully solution heat treated (fast heating and $530^{\circ} \mathrm{C} \times 2 \mathrm{~min}$ soaking for AA6082-T6) and quenched prior to ageing. The tests can also be divided to two groups: (I) Different heating periods, different holding temperatures and time were defined to determine the optimum ageing condition; 


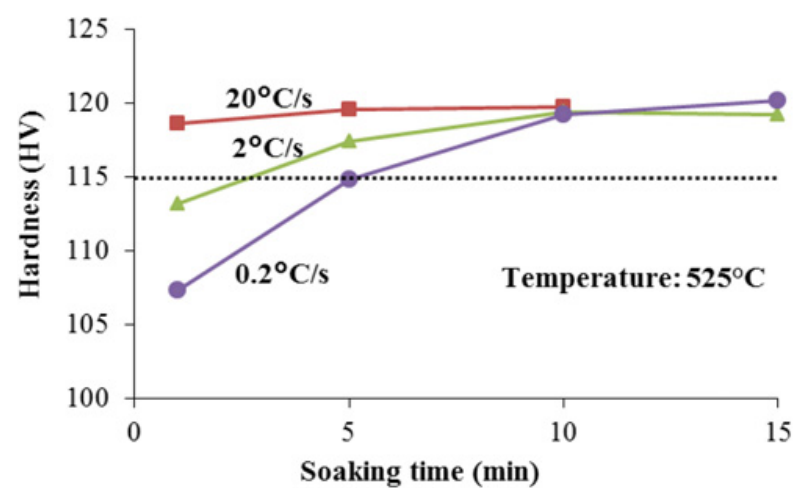

(a)

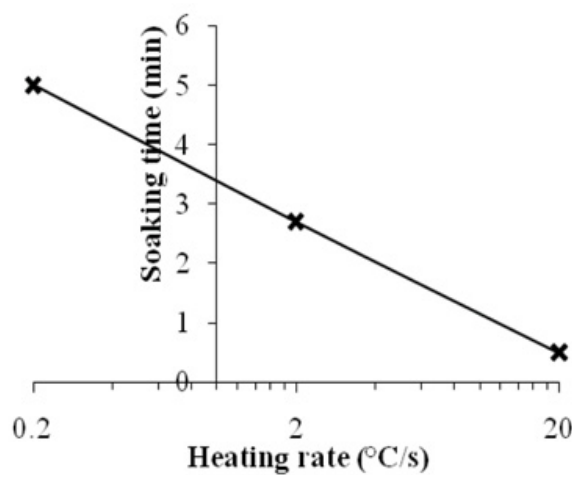

(b)

Figure 3. Effects of heating rate on (a) post hardness against soaking time and (b) soaking time to obtain $96 \%$ of full hardness, for AA6082-T6 being solution heat treated, followed by quenching and standard ageing.

(II) Quenched specimens were stretched to different strain levels to simulate the pre-deformation of HFQed components, and then aged under the optimum condition identified through group (I). After duplex ageing step, all specimens went through another step under the thermal condition of paint bake $\left(180^{\circ} \mathrm{C} \times 30 \mathrm{~min}\right)$. Post mechanical properties of heat treated specimens were evaluated by hardness testing and uniaxial tensile testing.

Heat treatments were conducted using laboratory chamber furnaces. K-type thermocouples were attached to specimens to monitor the temperature using a thermal data logger. Vickers hardness (HV) of specimens was tested using ZHU hardness testing machine, with $5 \mathrm{Kg}$ loading force. Tensile tests were conducted using an INSTRON material testing machine (Model 5584), with extensometer for strain measurement.

\section{Results and discussion}

\subsection{Fast solution heat treatment}

\subsubsection{Effects of heating rate}

The extent of SHT can be evaluated through the post hardness of the material. In this work, a condition can be considered as complete SHT only if the post hardness reaches $115 \mathrm{HV}$ (96\% of the as-delivered AA6082-T6). Figure 3 shows that SHT took longer time to complete when the material was heated at a lower rate. For the starting material of AA6082-T6, under the heating rate of $20^{\circ} \mathrm{C} / \mathrm{s}$, less than $1 \mathrm{~min}$ soaking time was needed to guarantee post hardness of $115 \mathrm{HV}$. When the heating rate decreased to $0.2^{\circ} \mathrm{C} / \mathrm{s}$, soaking time to complete SHT increased to $5 \mathrm{~min}$. By referring Fig. 1, it can be explained that, the $\beta^{\prime \prime}$ phase has more chance to transform to $\beta^{\prime}$ and $\beta$ phases, even small fractions of $\beta^{\prime}$ and $\beta$ phases existed before heating have more potential to grow bigger, while heating at a lower rate. This would cause a longer dissolution time for precipitates in larger sizes ( $\beta^{\prime}$ and $\beta$ phases). It indicates that a fast heating rate, especially from $200^{\circ} \mathrm{C}$ to $450{ }^{\circ} \mathrm{C}$, to avoid generation and growth of $\beta^{\prime}$ and $\beta$ phases is important for time and energy saving in the HFQ process.

\subsubsection{Effects of SHT temperature}

Figure 4 shows that more than 20 min was needed to dissolve the precipitates when AA6082-O was soaked at $525^{\circ} \mathrm{C}$. With increasing SHT temperature, the soaking time to complete SHT was reduced. Post hardness of $118 \mathrm{HV}$ could be achieved under the SHT condition of $570{ }^{\circ} \mathrm{C} \times 1 \mathrm{~min}$. 


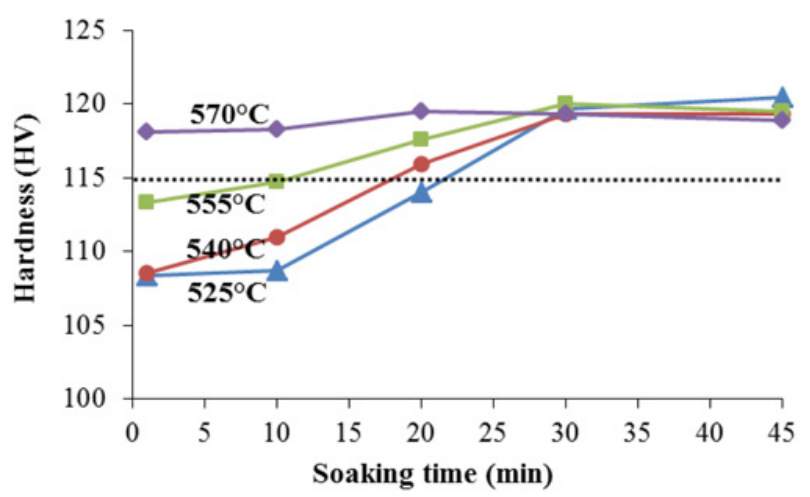

(a)

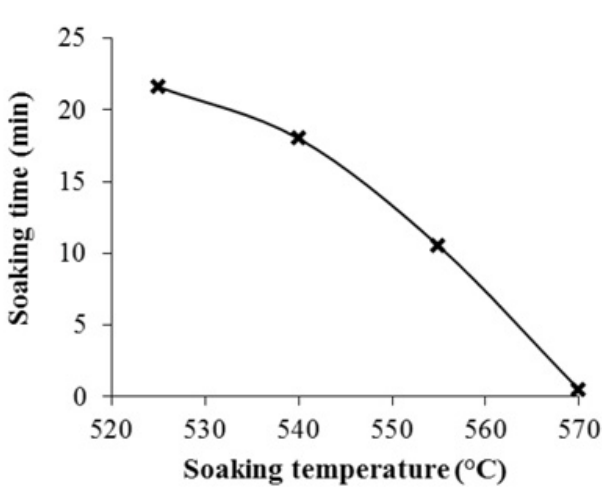

(b)

Figure 4. Effects of SHT temperature on (a) post hardness against soaking time and (b) soaking time to obtain $96 \%$ of full hardness, for AA6082-O being solution heat treated, followed by quenching and standard ageing.

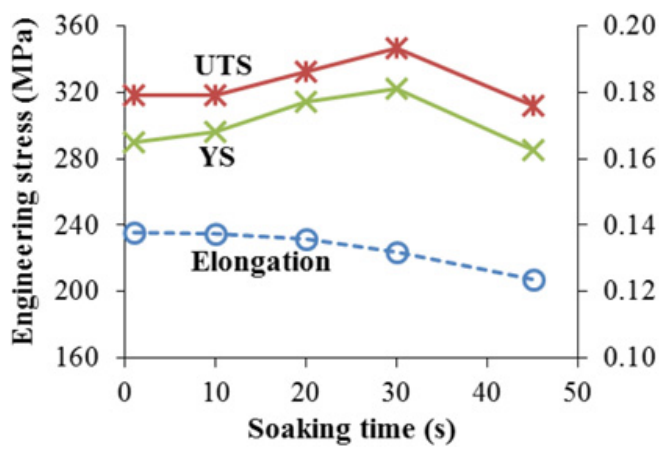

(a)

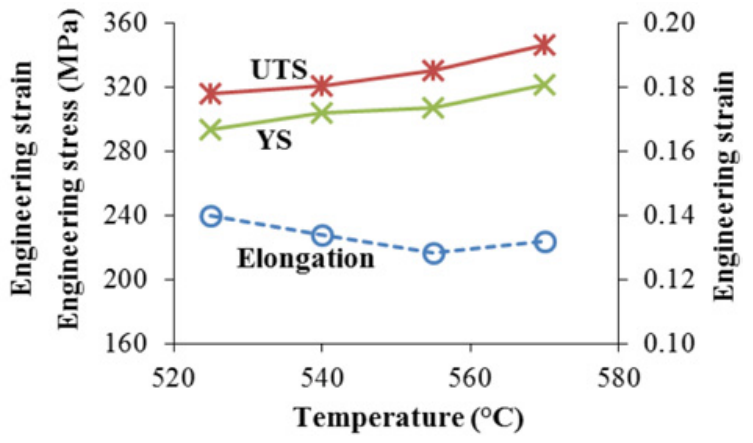

(b)

Figure 5. Post tensile properties of AA6082-O being solution heat treated at (a) $570{ }^{\circ} \mathrm{C}$ with different soaking time and (b) different temperatures for 30 min soaking, the followed by quenching and standard ageing.

Figure 5 shows the post tensile properties of specimens treated under different SHT conditions. UTS represents ultimate tensile strength which is the maximum engineering stress that the material can achieve. YS represents is $0.2 \%$ offset yield strength. Elongation is the engineering strain to failure. As can be seen from Fig. 5(a), under SHT temperature of $570^{\circ} \mathrm{C}$, either post strength or ductiliy dosen't change significantly with increasing SHT time. Also, as shown in Fig. 5(b), under the same soaking time of 30min, when SHT could be completed for all SHT temperatures, the changes of tensile properties with temperatures were not signicicant. The slight increase in strength is a positive trend. It confirms that fast SHT of AA6082-O can be realised by applying high SHT temperature of $570{ }^{\circ} \mathrm{C}$ with post mechanical properties guaranteed.

\subsection{Fast ageing}

\subsubsection{Optimize duplex ageing conditions}

It was found from resting results that, for the duplex ageing, the influence of gradual heating time in the range of 10-20 min was not sensitive on ageing conditions and material post properties. Thus the 


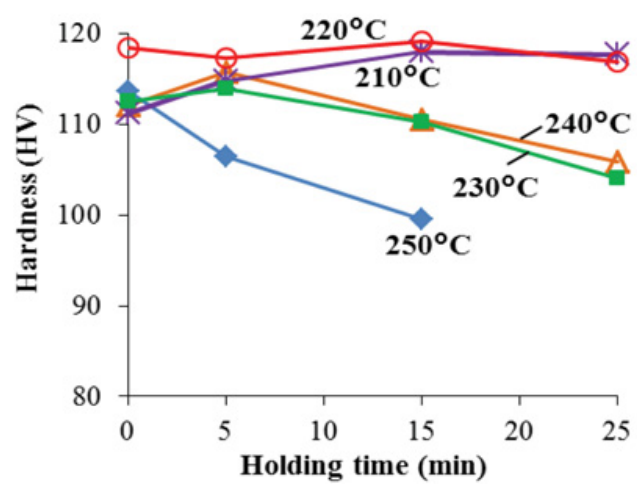

(a)

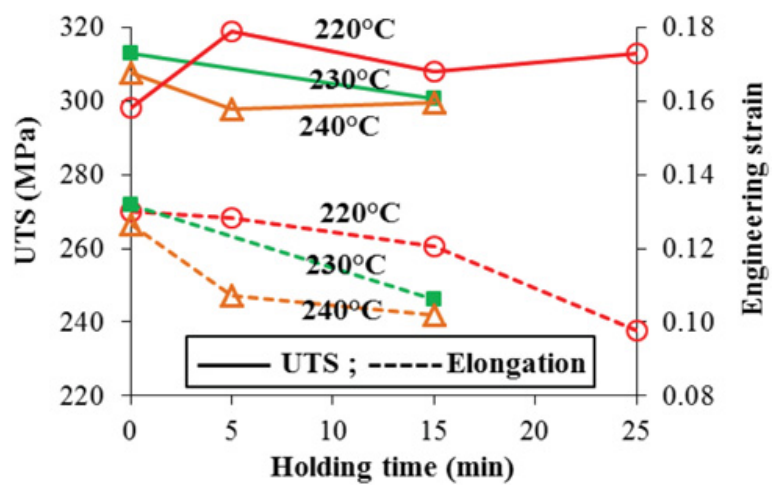

(b)

Figure 6. Post mechanical properties, (a) hardness and (b) UTS and elongation, against holding time at different duplex ageing temperatures.

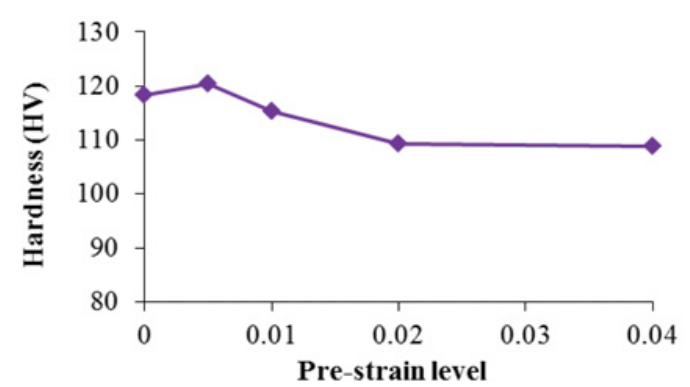

(a)

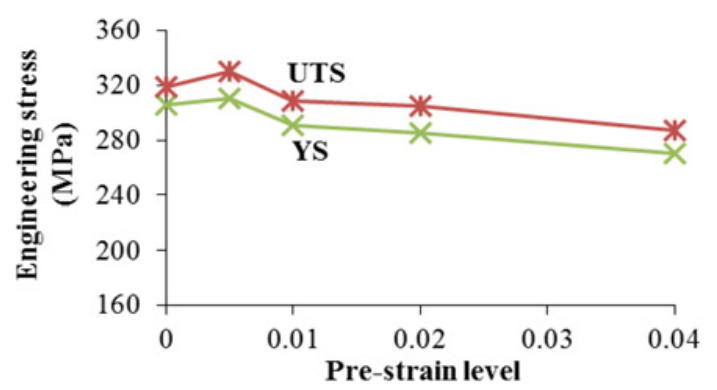

(b)

Figure 7. Effects of pre-deformation on precipitation hardening: (a) post hardness and (b) post strength.

heating time was fixed as $15 \mathrm{~min}$, with subsequent holding conditions altered for optimisation. Figure 6 shows the post mechacnial properties of material aged under different conditions. The hardness dropped with increasing holding time for the ageing temperatures of $250{ }^{\circ} \mathrm{C}, 240^{\circ} \mathrm{C}$, and $230^{\circ} \mathrm{C}$, which implies over-ageing of the material. This is also exhibited by the trend of UTS. Adversely, for $210^{\circ} \mathrm{C}$, an increasing trend of hardness is shown, which means a certain holding time was needed to allow peakageing to be achieved after paint bake. Considering the post properties of material and the stability of the process, $220^{\circ} \mathrm{C} \times 5$ min was determined as the optimum holding condition. The total processing time of duplex ageing process prior to paint bake would be 20 min only.

\subsubsection{Deformation effects}

A concern for artificial ageing of HFQed parts is the uniformity of final strength distribution. The ageing response of formed components could be affected by the degree of dislocation density generated during forming, which has to be investigated. It is noted that, as the specimens were deformed at room temperature, the level of strain should be much smaller than hot formed strain to represent the same degree of dislocation density. As shown in Fig. 7, under the optimum ageing condition defined in 4.2.1, the precipitation hardening increased with a small pre-strain level up to 0.005 and decreased with further straining until became stable. The cause of the phenomenon can be explained as: dislocations generated by pre-deformation could provide point defects as nucleation sites and reduce the requirement on 
activation energy for precipitates to form and grow. Thus the precipitation hardening could be enhanced. However, with further reduction in required activation energy due to increasing dislocations, the material could be over-aged. When the dislocations in the aluminium matrix gradually became saturated, the hardness and strength of the material tended to approach constant values. For the studied alloy, $90 \%$ of the full hardness and strength were guaranteed.

\section{Conclusions}

Based on the mechanism studies and experimental investigations, fast and energy-efficient SHT and ageing conditions have been identified for AA6082 for the HFQ process. A series of conclusions can be drawn: Fast heating $\left(20^{\circ} \mathrm{C} / \mathrm{s}\right)$ for SHT is important to avoid generation of $\beta^{\prime}$ and $\beta$ phases which can cause longer dissolution time. Fast SHT of AA6082-O can be realised by increasing SHT temperature to $570{ }^{\circ} \mathrm{C}$ for $1 \mathrm{~min}$ soaking, without sacrificing the post strength of material. Fast ageing process has been developed by integrating a duplex ageing process with paint bake process. The optimum condition for duplex ageing is $15 \mathrm{~min}$ heating $+220^{\circ} \mathrm{C} \times 5 \mathrm{~min}$ holding, with full post strength guaranteed and more than $90 \%$ time reduction compared to standard ageing. The section of formed components with large strains could be slightly over-aged under the optimised fast ageing condition; but $90 \%$ of the full hardness and strength can be obtained.

\section{References}

[1] R.P. Garrett, J. Lin, T.A. Dean, Adv. Mat. Res., 6-8, 673 (2005)

[2] A. Foster, T.A. Dean, J. Lin, Patent: EP 2324137 B1 (2008)

[3] E. Tan, B. Ogel, Turkish J. Eng. Env. Sci., 31, 53 (2007)

[4] M.S.K. Mohamed, Thesis, Imperial College London (2010)

[5] S. Esmaeili, X. Wang, D.J. Lloyd, W.J. Poole, Metall. Mater. Trans. A, 34, 751 (2003)

[6] J. van de Langkruis, W.H. Kool, C.M. Sellars, M.R. van der Winden, S. van der Zwaag, Mater. Sci. Eng., 299(1), 105 (2001)

[7] Y.G. An, L. Zhuang, H. Vegter, A. Hurkmans, Metall. Mater. Trans. A, 33A, 3121 (2002)

[8] D.C. Balderach, J.A. Hamilton, E. Leung, M.C. Tejeda, J. Qiao, E.M. Taleff, Mater. Sci. Eng., 339(1), 194 (2003) 